\title{
Emergence of Carbapenemase Producing Pathogens in Animals
}

Monika Bhardwaj', Bhoj R Singh²*, M Senthil Murugan², Prasannavadhana1 and Sakshi Dubey ${ }^{2}$

${ }^{1}$ Division of Bacteriology and Mycology, Division of Epidemiology, Indian Veterinary Research Institute, Izatnagar-243 122, India

${ }^{2}$ ICAR-Indian Veterinary Research Institute, Izatnagar-243122, India

\begin{abstract}
Carbapenems are beta $(\beta)$-lactam antibiotics active against wide range of bacteria. Carbapenem resistance may be outcome of efflux pump activation, alteration in protein binding proteins, production of carbapenemases which degrade carbapenems. There are number of bacteria producing different types of carbapenemases like NDM (Enterobacteriaceae), IMP (Pseudomonas aeruginosa), IMI (Enterobacter cloacae), KPC (Klebsiella pneumonia), OXA-23, OXA-24/40, OXA-58-type (Acinetobacter baumannii), VIM (Acinetobacter baumannii) etc. Carbapenem resistance is emerging throughout the world due to interspecies transfer of genetic elements carrying genes for carbapenemase production. It is very difficult to control spread of resistant strains because of the continuous threshold of selection present in forms of presence of carbapenems in environment created through wide spread clinical use. To control infection of carbapenem resistant bacteria there are limited options available for treatment. Many a time carbapenem resistant bacteria show pan-resistance and such bacterial infection become life-threatening and cannot be treated with available last resort antibiotics like polymin B, tigecyclin and colistin. Infection of carbapenem resistant bacteria can be controlled using two or more antibiotics or antibiotic+ herbal drug combination or herbal drugs like (carvacrol, cinnamon, holy-basil oil, lemon grass oil) etc. The herbal drugs may be used as first line of treatment against carbapenem resistant bacteria instead of antibiotics. But, how? It is still not very lucid. Besides it, probiotics and homeopathic therapy has also been recommended with no sufficient data to establish their efficacy.
\end{abstract}

Keywords: Carbapenem; Carbapenemase; Resistance; Animals; Herbal drugs; Mobile genetic elements; NDM; VIM; OXA; KPC

\section{Introduction}

Carbapenems are broad-spectrum beta ( $\beta$ )-lactam antibiotics used for treatment of serious infections. They are considered as the last-line therapy against multidrug-resistant (MDR) Gram-negative bacterial infections like extended spectrum $\beta$-lactamase (ESBL) producing Enterobacteriaceae, Pseudomonas spp., Acinetobacter spp. Etc [1-5]. If a bacterial strain carries carbapenemase production potential there are only few or sometimes no options to treat the infection. Carbapenems are used extensively due to increased prevalence of cephalosporinresistant pathogens. Because of the emergence of bacterial strains producing carbapenemases, resistance to carbapenems is increasing throughout the world that may seriously limits the clinical efficacy of carbapenam antibiotics [6-13]. Patients infected with carbapenem resistant Enterobacteriacae are not easy to treat due to limited available options.

Carbapenem resistant bacteria mostly carry genes responsible for resistance to the antibiotics like fluoroquinolones, trimethoprimsulfamethoxazole and aminoglycosides on same transposon [14]. There are different types of carbapenemases produced by different bacteria like SME (Serratia marcescens), NMC and IMI (Enterobacter cloacae), KPC (Klebsiella pneumonia), GES (Pseudomonas aeruginosa), SFC (Serratia fonticola), OXA-23, OXA-24/40, OXA-58-type (Acinetobacter baumannii), OXA-48-type (Klebsiella pneumoniae), OXA-54 (Acinetobacter baumannii), OXA-55 (Shewanella oneidensis), VIM (Acinetobacter baumannii), NDM (Enterobacteriaceae), IMP(Pseudomonas aeruginosa) and many more. These enzymes are responsible for reduced susceptibility/ resistance to carbapenems.

Carbapenem hydrolyzing enzymes are broadly classified into two types on the basis of reactive site of the enzymes: serine carbapenemases and metallo- $\beta$-lactamases. Both the types of enzymes are inducible through exposure of bacteria to $\beta$-lactams. Beta lactamases are produced by number of bacteria, genes encoded may house either on chromosome or on plasmid(s). The first few metallo- $\beta$-lactamases, chromosomally encoded, enzymes were detected in Bacillus cereus (BCI, BCII) (15-16), Stenotrophomonas maltophilia (L1) [17] and Aeromonas spp (CphA) [18]. In case of plasmid borne MBLs, gene cassettes possess mobile MBL genes viz., blaVIM, blaIMP, blaGIM, blaSIM and blaKMH. Magiorakos and coworkers [19] revealed that many carbapenemase-producing $(\mathrm{CP})$ strains may carry additional resistance determinants to other non- $\beta$-lactam antibiotics also; those organisms are called as pan drug-resistant (PDR) or extensively drugresistant (XDR).

\section{Emergence of Antimicrobial Drug Resistance}

Emergence of antimicrobial drug resistance (ADR) and multiple ADR (MDR) in microbes has been discussed and reviewed extensively over the time [20-25]. Several reasons have been attributed for emergence of ADR and MDR but no cure has still been possible to reverse this process. Scientists fear that if the process is not reversed in time than the day is not far away when number of incurable cases will be out of clinical control and beyond reach of health management agencies [24-26]. Bacteria develop ADR through complex interactions within their community, through de-novo mutation under clinical antibiotic use and through acquisition of genes under antibiotic stress [20-25] and even under natural environmental stresses [26,27]. However, the spread of ADR and MDR usually occurs through selection under nonclinical and clinical antibiotic stresses or through

*Corresponding author: Bhoj R Singh, Head Division of Epidemiology, Indian Veterinary Research Institute, Izatnagar-243 122, India, Tel: +91-8449033222; E-mail: brs1762@gmail.com

Received April 28, 2015; Accepted May 09, 2015; Published May 16, 2015

Citation: Bhardwaj M, Singh BR, Murugan MS, Prasannavadhana, Dubey S (2015) Emergence of Carbapenemase Producing Pathogens in Animals. Pharm Anal Acta 6: 379. doi:10.4172/21532435.1000379

Copyright: (c) 2015 Bhardwaj M, et al. This is an open-access article distributed under the terms of the Creative Commons Attribution License, which permits unrestricted use, distribution, and reproduction in any medium, provided the original author and source are credited. 
acquisition of mobile genes that have evolved over the time in bacteria and in their environment $[20,26]$. The reservoir of resistance genes in the environment exists since time immemorial due to a mix of naturally occurring resistance and those natural antimicrobials present in animal and human waste, and the selective effects of environmental pollutants $[22,24,26]$. It is not necessary that only antibiotic stress will be responsible for emergence and spread of ADR, natural stress arising from global warming as a result of pollution may be an instrumental factor. In recent studies [27] it has been shown that Escherichia coli may evolve resistance when grown at elevated temperature. Now, we understand that of most of the reasons behind emergence and spread of ADR and MDR are anthropogenic activities, more important than any other single factor [26]. Therefore, our future is in our hands and self-regulation might be the key for the still unresolved riddle of ADR evolution and spread in microbes.

\section{History of Carbapenem Resistance}

Guiana extended spectrum (GES) $\beta$-lactamase was first observed in a Klebsiella pneumoniae isolate from French Guiana in 2000. Soon after in 2001, Klebsiella pneumoniae carbapenemase designated as KPC was identified from a Klebsiella isolate [28]. The KPC was encoded by a highly transmissible gene, spread widely throughout world. Verona integron encoded metallo- $\beta$-lactamase (VIM) was first metallo- $\beta$ lactamase identified from a $P$. aeruginosa isolated in 1997 in Italy. VIM-2 was detected from an isolate of $P$. aeruginosa again from a strain isolated in France in year 1996. Again from P. aeruginosa one more $\beta$-lactamase, Sao Paulo metallo- $\beta$-lactamases (SPM-1) was identified from Sao Paulo, Brazil. In year 2002, German imipenemase (GIM1) was first detected in bacteria in Germany. However, transferable carbapenem resistance due to IMP was first detected in a $P$. aeruginosa isolate from Japan in 1990. Besides it, IMP-2 was observed in $A$. baumannii in Italy. Next, from Seoul, Seoul imipenemase (SIM-1) was detected in $P$. aeruginosa and A. baumannii from imipenem resistant isolates. New Delhi metallo- $\beta$-lactamase (NDM-1) was first reported from a K. pneumoniae isolate obtained from a Swedish patient in year 2009. NDM-1 was initially identified in Klebsiella pneumoniae [29] and then in E .coli. Gene responsible for it, blaNDM-1 was housed in $180 \mathrm{~kb}$ plasmid. The gene product confers high level resistance to all penicillins, cephalosporins, cefoxitin, carbapenems, ciprofloxacin and aztreonam. In 1985, first OXA enzyme with carbapenemase activity was identified in A. baumannii from Scotland in a previously known imipenem resistant Acinetobacter (ARI-1) and since then it is detected all over the world in many bacteria.

\section{Epidemiology of Carbapenam Resistant Pathogens}

Carbapenem resistance due to production of carbapenemases has increased in different countries around the world [30,23]. This is mainly due to travelling across the countries while being infected with antibiotic-resistant organisms and global open trade of animals, their products, goods and foods. The highest infection rate is detected among the travelers to Indian subcontinent and African countries. Klebsiella pneumoniae carbapenemase (KPC) has been reported in number of countries like India, China, Turkey, Israel, United Kingdom and United States. The KPC enzymes have been observed in K. pneumoniae, K. oxytoca, P. aeruginosa, E. coli, Enterobacter cloacae, E. aerogenes, Salmonella enterica, Serratia marcescens and Citrobacter freundi. KPC2 producing K. pneumoniae were isolated from Israel and Columbia.

In case of GES enzymes, they have been identified across Asian, Europeon and African countries. VIM and IMP enzymes are also detected in pathogens all over the world. Since the year 2009, NDM
MBL detection was considered as more common over VIM-2. The gene encoding NDM-1 is located on mobile genetic element, thus results in rapid spread across the species and countries. Many variants of $\operatorname{NDM}(>12)$ have been identified in last few years and NDM-5 has been even detected in several non-clinical bacterial isolates from animals. On other hand, GIM, SIM and SPM enzymes remained restricted to countries of their origin. Regarding OXA-48, it is now reported from Turkey, China, India, and the United Kingdom. OXA-58 was isolated from Acinetobacter spp. in France, Greece, Romania, Italy, Turkey, Kuwait and Argentina. Fischer et al. [31-34] speculated that wild birds and animals may act as a reservoir for strains possessing carbapenemase encoding genes, as Salmonella producing NDM-1 has been isolated from a black kite and E. coli having NDM-5 has been isolated from Thamin dear (unpublished data from our lab).

\section{Carbapenem Resistance}

Emergence of acquired carbapenemases and their worldwide dissemination is a major global threat to antibiotic era [30,33,35-39]. Carbapenem resistance is either due to production of $\beta$-lactamases, or activation of efflux pumps, and or mutations that alter expression of porins and penicillin binding proteins (PBPs). The combination of these mechanisms results in increased resistance to carbapenems in bacterial species such as $K$. pneumoniae, $P$. aeruginosa, and $A$. baumannii [40-42].

Carbapenem resistance is of two types: intrinsic and acquired. Intrinsic resistance to carbapenems is because of inherent properties like low permeability of bacterial membranes, low affinity of penicillin binding proteins (PBPs), presence of species-specific carbapeneminactivating enzymes and presence of multidrug efflux pumps and is common in enterococci [43]. Acquired carbapenem resistance is due to presence of exogenous genetic material such as plasmids, transposons and insertion sequence common region (ISCR) elements containing genes coding for carbapenemase production. It is common in Enterobacteriaceae members [44].

Mechanism of resistance to carbapenems is different for Grampositive cocci and Gram-negative rods. In case of Gram-positive cocci, carbapenem resistance is due to substitutions in amino acid sequences of PBPs or production of a new carbapenem-resistant PBP [45-47]. In case of Gram-negative rods, porin loss, alterations in PBPs, expression of $\beta$-lactamases and efflux pumps are responsible for carbapenem resistance $[11,48]$.

\section{Carbapenam Resistance in Animal Pathogens}

Carbapenemase producing $(\mathrm{CP})$ bacteria has been reported in food-producing animals and their environment [44,49-54]. Salmonella Paratyphi B variant Java, $S$. Saintpaul and $S$. Virchow with $C P$ potential have been reported from buffalo calves and beef in India [55]. The CP E. coli from oysters, water, shrimps and pond environment have been reported in Brazil [56-57]. The CP Salmonella Corvallis isolated from a wild bird has also been reported in Germany [34]. NDM-1-producing E. coli were reported from companion animals (cats and dogs) in USA [58]. Wang and coworkers [52] found blaNDM-1 gene in A. lwoffii isolated from a chicken in a broiler farm. Stolle et al. [59] reported OXA48 in E. coli and K. pneumoniae from dogs. Kempf et al. [60] described OXA-23-like CP A. baumannii from human head lice in Senegal. Poirel et al. [51] detected $9 \mathrm{CP}$ isolates of Acinetobacter genomospecies on a dairy cattle farm in France in 2010. The carbapenemase resistance in these isolates was due to OXA-23 enzyme encoded by the gene blaOXA-23. The same gene was also detected in Acinetobacter spp. from two horses in Belgium [61]. Fischer et al. [49] described three CP 
Salmonella spp. isolates from two fattening pig farms and one broiler farm in Germany.

Kumsa et al. [62] conducted search for CP strains in Ethiopia to determine the presence of Acinetobacter species in lice and Melophagus ovinus (sheep ked) of animals in year 2011. During the study the isolates were tested for carbapenemase resistance-encoding genes like blaOXA-58, blaOXA-23, blaOXA-24, blaOXA-51 and blaNDM-1. However, no positive result was recorded in their study. Stolle et al. [59) described transmission of a K. pneumoniae strain having OXA-48 carbapenemase to several dogs in a veterinary clinic. It suggests that hand hygiene is as important here as in human medicine to prevent and control infections and to limit the spread of resistant bacteria.

In India, in a recent study on $279 \mathrm{E}$. coli isolates from calves, 80 isolates were found resistant to carbapenem drugs. These isolates were subjected to PCR targeting NDM, VIM, OXA, KPC and IMP genes. One isolate was producing the metallo beta lactamase enzyme VIM - genotypically confirmed by PCR [63]. Besides, several CP strains possessing VIM, NDM and OXA genes have been recently reported from dears, tigers, diarrhoeic as well as healthy pigs and aborting cows (Research Advisory Committee meeting of IVRI, 21-23 April, 2015, unpublished).

\section{Control of Carbapenem Resistant Infections}

Though options available are few still we are not away of hope, some of alternative strategies for control of CP bacterial infection are:

\section{Alternative antibiotic}

Polymyxin B: It is considered as last-line antibiotics for multidrugresistant $A$. baumanni and $P$. aeruginosa. Polymixin $\mathrm{B}$ can be used at high doses regardless of the presence of renal dysfunction [64]. But polymyxins can only achieve limited bacterial killing against isolates with high minimal inhibitory concentrations (MICs), though considerably high concentrations of unbound polymyxin are achievable in patients [65-66].

Colistin: Colistin is a polypeptide antibiotic, consists of colistin A and B. The antibiotic came in use in the 1960s. It is again becoming common for use against multidrug resistant bacteria as alone or in combination form with other antibiotic [67-69]. But at effective doses colistin can cause nephrotoxicity. Colistin methane sulphonate sodium (CMS) is converted to colistin in urine leading to high urinary concentrations [65]. In India, colistin resistance is quite common in bacteria isolated from animals [70].

Tigecycline: Tigecycline was approved by the Food and Drug Administration (FDA) in year 2005 [71-72]. The antibiotic is used against polymixin $B$ resistant carbapenem resistant Enterobacteriaceae and A. baumannii. The clinical use of antibiotic is limited for controlling infection in urinary tract and for primary blood-stream infections. Tigecycline is not very active against $P$. aeruginosa [73].

Fosfomycin: Fosfomycin, a phosphonic acid derivative, used as an alternative against carbapenem resistant Enterobacteriaceae [7478]. Fosfomycin is used for the treatment of non-complicated urinary tract infections because it rapidly reaches high urinary concentrations [79]. It shows excellent activity in vitro against strains resistant to both colistin and tigecycline. The antibiotic is less frequently used against $P$. aeruginosa because of higher MICs and a higher potential for development of resistance against it [80-82]. Some other antibiotics are also recommended like aminoglycosides, quinolones, trimethoprim, chloramphenicol and temocillin but only after their proper MIC determination to the pathogen.

\section{Combinational therapy}

Antibiotic combinations have been proposed as the best way to treat carbapenem resistant organisms like colistin along with tigecycline, colistin with a carbapenem, carbapenem along with fosfomycin, carbapenem with an aminoglycoside [83-86] and fosfomycin with an aminoglycoside [87]. Gentamicin is the recommended antibiotic which can be used against KPC and VIMproducing Enterobacteriaceae with the highest in vitro activity [88-89]. Aztreonam, ceftazidime can also be combined with aminoglycoside like amikacin or genatmicin for use in combination therapy against carbapenem resistant bacteria [70].

\section{Probiotics}

Probiotics are used to alter the gut microflora so that carbapenem resistant bacteria cannot colonize in it $[23,24]$. There are number of commercial supplements, enough to boost immune system and help to protect from developing a serious infection. These strains include Lactobacillus casei, Lactobacillus plantarum, Lactobacillus salivarius, Lactobacillus acidophilus, Bifidobacterium bifidum, Bifidobacterium breve and Bifidobacterium lactis.

\section{Alternative therapies}

Herbal drugs: Oregano oil (containing carvacrol) disrupts the protective cell membrane of the carbapenemase resistant bacteria. Olive leaf extract is also considered as natural antibacterial agent against antibiotic resistant isolates. According to Jazani group's studies [90] fennel essential oil extracts has antimicrobial activity against multidrug resistant $A$. baumannii. Fahey et al. [91] found that pomegranate rind extract has antimicrobial activity against multi-drug resistant $P$. aeruginosa. Khan et al. [92] found that cinnamon and clove extract has antibacterial activity against multi-drug resistant strains of $E$. coli and Klebsiella. Herbal drugs can modulate the effect of antibiotics available against carbapenem resistant bacteria. Colistin antibacterial activity can be enhanced by cinnamon oil as well as carvacrol [70]. The herbal drugs namely holy basil oil (MIC $20 \mathrm{mcg}$ to $>2560 \mathrm{mcg} \mathrm{mL}^{-1}$ ), lemon grass oil (MIC $5 \mathrm{mcg}$ to $>5000 \mathrm{mcg} \mathrm{mL}^{-1}$ ), cinnamon oil (MIC $10 \mathrm{mcg}$ to $>1280 \mathrm{mcg} \mathrm{mL}^{-1}$ ), and carvacrol (MIC $5 \mathrm{mcg}$ to $>5000 \mathrm{mcg} \mathrm{mL}^{-1}$ ) have shown potential for use to control CP strains of bacteria at least in vitro [70].

\section{Homeopathy}

Veterinary homeopathy is use of homeopathy in animals. The homeopathic products are not recommended veterinary medicine in the US. The field can be explored in future to treat against carbapenem resistant bacteria.

\section{Conclusions}

The emergence and rapid spread of carbapenem resistance bacteria is an important threat to public health. Antibiotic options currently in use against carbapenemase producer microbes include tigecycline, colistin, polymyxin B, fosfomycin, and aminoglycosides. There are number of limitations associated with these drugs like increase in resistance, less efficacy and toxicity. So, these antibiotics have been used as combination therapy to reduce the side effects. Moreover, carbapenems are considered as last line of treatment for resistant bacteria but due to production of carbapenemases, the carbapenems are not effective against multidrug resistant bacteria. Due to limited therapeutic options more emphasis should be laid on control strategies for preventing their spread. Also, carriers of resistant isolates should be identified at early stages. Excessive use of broad-spectrum antibiotics 
Citation: Bhardwaj M, Singh BR, Murugan MS, Prasannavadhana, Dubey S (2015)Emergence of Carbapenemase Producing Pathogens in Animals Pharm Anal Acta 6: 379. doi:10.4172/21532435.1000379

should be controlled. For the treatment of carbapenem resistant bacteria some alternatives should be used with limited side effects like herbal drugs.

\section{References}

1. Bradley JS, Garau J, Lode H, Rolston KV, Wilson SE, et al. (1999) Carbapenems in clinical practice: a guide to their use in serious infection.Int $\mathrm{J}$ Antimicrob Agents 11: 93-100

2. Paterson DL (2000) Recommendation for treatment of severe infections caused by Enterobacteriaceae producing extended-spectrum ß-lactamases (ESBLs). Clinical Microbiology and Infection 6: 460-463.

3. Paterson DL (2002) Serious infections caused by enteric gram-negative bacilli-mechanisms of antibiotic resistance and implications for therapy of gram-negative sepsis in the transplanted patient. Seminars in Respiratory Infections 17: 260-264

4. Paterson DL, Bonomo RA (2005) Extended-spectrum beta-lactamases: a clinical update.Clin Microbiol Rev 18: 657-686.

5. Torres JA, Villegas MV, Quinn JP (2007) Current concepts in antibiotic-resistant gram-negative bacteria.Expert Rev Anti Infect Ther 5: 833-843.

6. Chouchani C, Marrakchi R, EI Salabi A (2011) Evolution of $\hat{I}^{2}$-lactams resistance in Gram-negative bacteria in Tunisia. Crit Rev Microbiol 37: 167-177.

7. Gaibani P, Ambretti S, Berlingeri A, et al. (2011) Rapid increase of carbapenemase-producing Klebsiella pneumoniae strains in a large Italian hospital: surveillance period 1March-30 September 2010. European Surveillance 16: 19800

8. Gopalakrishnan R, Sureshkumar D (2010) Changing trends in antimicrobia susceptibility and hospital acquired infections over an 8 year period in a tertiary care hospital in relation to introduction of an infection control programme. Journal of Association of Physicians India 58: 25-31.

9. Livermore DM, Warner M, Mushtaq S, Doumith M, Zhang J, et al. (2011) What remains against carbapenem-resistant Enterobacteriaceae Evaluation of chloramphenicol, ciprofloxacin, colistin, fosfomycin, minocycline, nitrofurantoin temocillin and tigecycline.Int J Antimicrob Agents 37: 415-419.

10. Nicasio AM, Kuti JL, Nicolau DP (2008) The current state of multidrug-resistant gram-negative bacilli in North America.Pharmacotherapy 28: 235-249.

11. Nordmann P, Picazo JJ, Mutters R, Korten V, Quintana A, et al. (2011) Comparative activity of carbapenem testing: the COMPACT study. J Antimicrob Chemother 66: 1070-1078.

12. Patel G, Bonomo RA (2011) Status report on carbapenemases: challenges and prospects. Expert Rev Anti Infect Ther 9: 555-570.

13. Rossi F1 (2011) The challenges of antimicrobial resistance in Brazil. Clin Infect Dis 52: 1138-1143.

14. Bratu S, Tolaney P, Karumudi U, et al. (2005) Carbapenemase-producing Klebsiella pneumoniae in Brooklyn, NY: molecular epidemiology and in vitro activity of polymyxin $B$ and other agents. Journal of Antimicrobial Chemotherapy 56: $128-132$

15. Kuwabara S, Abraham EP (1967) Some properties of two extracellular betalactamases from Bacillus cereus 569/H.Biochem J 103: 27C-30C.

16. Lim HM, Pène JJ, Shaw RW (1988) Cloning, nucleotide sequence, and expression of the Bacillus cereus $5 / B / 6$ beta-lactamase II structural gene.J Bacteriol 170: 2873-2878.

17. Saino Y, Kobayashi F, Inoue M, Mitsuhashi S (1982) Purification and properties of inducible penicillin-lactamase isolated from Pseudomonas maltophilia. Antimicrobial Agents and Chemotherapy 22: 564-570.

18. laconis JP, Sanders CC (1990) Purification and characterization of inducible beta-lactamases in Aeromonas spp.Antimicrob Agents Chemother 34: 44-51.

19. Magiorakos AP, Srinivasan A, Carey RB, et al. (2012) Multidrug-resistant, extensively drug-resistant and pandrug-resistant bacteria: an international expert proposal for interim standard definitions for acquired resistance. Clinical microbiology and infection: the official publication of the European Society of Clinical Microbiology and Infectious Diseases 18: 268-281.

20. Tenover FC, McGowan JE Jr (1996) Reasons for the emergence of antibiotic resistance.Am J Med Sci 311: 9-16.
21. Kumar S, Singh BR (2013) An Overview on Mechanisms and Emergence of Antimicrobials Drug Resistance. Advances in Animal and Veterinary Sciences. 1 (2S): 7-14.

22. Singh BR (2011) Drug resistant bacteria in the environment: In: Environmental Security (Ed, Garg SR) IBDC Publishers, Lucknow, India. Pp. 313-326.

23. Singh BR (2013) Antimicrobial sensitivity assay and antimicrobial chemotherapy in Animals: A Practical approach. In: Diseases of Animals: Diagnosis and Management (Eds. Singh BR and Somvanshi R), Indian Veterinary Research Institute, Izatnagar- 243 122, UP. Pp: 7-31.

24. Singh BR (2013) Antimicrobial drug use and its implications. http://www. slideshare.net/singh_br1762/antimicrobial-drug-use-and-its-implications.

25. Levy SB, Marshall B (2004) Antibacterial resistance worldwide: causes, challenges and responses.Nat Med 10: S122-129.

26. Wellington EM, Boxall AB, Cross P, Feil EJ, Gaze WH, et al. (2013) The role of the natural environment in the emergence of antibiotic resistance in gramnegative bacteria.Lancet Infect Dis 13: 155-165.

27. Rodríguez-Verdugo A, Gaut BS, Tenaillon O (2013) Evolution of Escherichia coli rifampicin resistance in an antibiotic-free environment during thermal stress.BMC Evol Biol 13: 50.

28. Yigit H, Queenan AM, Anderson GJ, et al. (2001) Novel carbapenemhydrolyzing beta-lactamase, KPC-, from a carbapenem-resistant strain of Klebsiella pneumoniae. Antimicrobial Agents and Chemotherapy 45: 1151-1161.

29. Yong D, Toleman MA, Giske CG, et al. (2009) Characterization of a new metallo-ß-lactamase gene, blaNDM-, and a novel erythromycin esterase gene carried on a unique genetic structure in Klebsiella pneumonia sequence type 14 from India. Antimicrobial Agents and Chemotherapy 53: 5046-5054.

30. Cantón R, Akóva M, Carmeli Y, Giske CG, Glupczynski Y, et al. (2012) Rapid evolution and spread of carbapenemases among Enterobacteriaceae in Europe.Clin Microbiol Infect 18: 413-431.

31. Gupta N, Limbago BM, Patel JB, Kallen AJ (2011) Carbapenem-resistant Enterobacteriaceae: epidemiology and prevention. Clinical Infectious Diseases 53: $60-67$.

32. Hawkey PM (2008) The growing burden of antimicrobial resistance.J Antimicrob Chemother 62 Suppl 1: 1-9.

33. Nordmann P, Naas T, Poirel L (2011) Global spread of Carbapenemaseproducing Enterobacteriaceae.Emerg Infect Dis 17: 1791-1798.

34. Fischer J, Schmoger S, Jahn S, Helmuth R, Guerra B (2013) NDM-1 carbapenemase-producing Salmonella enterica subsp. enterica serovar Corvallis isolated from a wild bird in Germany. Journal of Antimicrobial Chemotherapy 68: 2954-2956.

35. Cornaglia G, Giamarellou H, Rossolini GM (2011) Metallo-I²-lactamases: a last frontier for $\hat{I}^{2}$-lactamsLancet Infect Dis 11: 381-393.

36. Queenan AM, Bush K (2007) Carbapenemases: the versatile beta-lactamases Clin Microbiol Rev 20: 440-458, table of contents.

37. Moellering RC Jr (2010) NDM-1--a cause for worldwide concern.N Engl J Med 363: 2377-2379.

38. Tzouvelekis LS, Markogiannakis A, Psichogiou M, Tassios PT, Daikos GL (2012) Carbapenemases in Klebsiella pneumoniae and other Enterobacteriaceae: an evolving crisis of global dimensions.Clin Microbiol Rev 25: 682-707.

39. Walsh TR1 (2010) Emerging carbapenemases: a global perspective.Int $J$ Antimicrob Agents 36 Suppl 3: S8-14.

40. Limansky AS, Mussi MA, Viale AM (2002) Loss of a 29-kilodalton oute membrane protein in Acinetobacter baumannii is associated with imipenem resistance. J Clin Microbiol 40: 4776-4778.

41. Mena A (2006) Characterization of a large outbreak by CTX-M-1 producing Klebsiella pneumoniae and mechanisms leading to in vivo carbapenem resistance development. Journal of Clinical Microbiology 44: 2831-2837.

42. Rodriguez-Martinez JM, Poirel L, Nordmann P (2009) Molecular epidemiology and mechanisms of carbapenem resistance in Pseudomonas aeruginosa. Antimicrobial Agents and Chemotherapy 53: 4783-4788.

43. Lee EW, Huda MN, Kuroda T, Mizushima T, Tsuchiya T (2003) EfrAB, an ABC multidrug efflux pump in Enterococcus faecalis.Antimicrob Agents Chemothe 47: 3733-3738. 
Citation: Bhardwaj M, Singh BR, Murugan MS, Prasannavadhana, Dubey S (2015)Emergence of Carbapenemase Producing Pathogens in Animals Pharm Anal Acta 6: 379. doi:10.4172/21532435.1000379

44. Smet A, Martel A Persoons D, Dewulf J, Heyndrickx M, et al (2010) Broadspectrum ß-lactamases among Enterobacteriaceae of animal origin: molecula aspects, mobility and impact on public health. FEMS Microbiology Reviews 34: 295-316.

45. Katayama Y, Zhang HZ, Chambers HF (2004) PBP 2a mutations producing very-high-level resistance to beta-lactams.Antimicrob Agents Chemother 48: 453-459.

46. Koga T (2009) Affinity of tomopenem (CS-023) for penicillin-binding proteins in Staphylococcus aureus, Escherichia coli and Pseudomonas aeruginosa. Antimicrobial Agents and Chemotherapy 53: 1238-1241.

47. Matsumoto A, Hosoya M, Kawasaki Y, Katayose M, Kato K, et al. (2007) The emergence of drug-resistant Streptococcus pneumoniae and host risk factors for carriage of drug-resistant genes in northeastern Japan. Jpn J Infect Dis 60: 10-13.

48. Pearson JP, Van Delden C, Iglewski BH (1999) Active efflux and diffusion are involved in transport of Pseudomonas aeruginosa cell-to-cell signals.J Bacteriol 181: 1203-1210.

49. Fischer J, Rodríguez I, Schmoger S, Friese A, Roesler U, et al. (2012) Escherichia coli producing VIM-1 carbapenemase isolated on a pig farm.J Antimicrob Chemother 67: 1793-1795.

50. Fischer J, Rodríguez I, Schmoger S, Friese A, Roesler U, et al. (2013) Salmonella enterica subsp. enterica producing VIM-1 carbapenemase isolated from livestock farms.J Antimicrob Chemother 68: 478-480.

51. Poirel L, Berçot B, Millemann Y, Bonnin RA, Pannaux G, et al. (2012) Carbapenemase-producing Acinetobacter spp. in Cattle, France. Emerg Infect Dis 18: $523-525$

52. Wang Y, Wu C, Zhang Q, Qi J, Liu H, et al. (2012) Identification of New Delhi metallo- $\left.\right|^{2}$-lactamase 1 in Acinetobacter Iwoffii of food animal origin.PLoS One 7: e37152

53. Woodford N, Wareham DW, Guerra B, Teale C (2014) Carbapenemaseproducing Enterobacteriaceae and non-Enterobacteriaceae from animals and the environment: an emerging public health risk of our own making. J Antimicrob Chemother 69: 287-291.

54. Zhang WJ, Lu Z, Schwarz S, Zhang RM, Wang XM, et al. (2013) Complete sequence of the bla(NDM-1)-carrying plasmid pNDM-AB from Acinetobacter baumannii of food animal origin. J Antimicrob Chemother 68: 1681-1682.

55. Singh S, Agarwal RK, Tiwari SC, Singh H (2012) Antibiotic resistance pattern among the Salmonella isolated from human, animal and meat in India. Tropical Animal Health and Production 44: 665-674.

56. Vieira RH, Carvalho EM, Carvalho FC, Silva CM, Sousa OV, et al. (2010) Antimicrobial susceptibility of Escherichia coli isolated from shrimp (Litopenaeus vannamei) and pond environment in northeastern Brazil.J Environ Sci Health B 45: 198-203.

57. Vieira RHS, Atayde MA, Carvalho EMR, Carvalho FCT, Fonteles Filho AA (2008) Fecal contamination of the mangrove oyster Crassostrea rhizophorae and the cultivation water at the river pacoti estuary (Eusebio - Ceara State) identification and isolation of Escherichia coli and its susceptibility to different antimicrobians. Brazilian Journal of Veterinary Research and Animal Science 45: 180-189.

58. Shaheen BW, Nayak R, Boothe DM (2013) Emergence of a New Delhi metallo$\hat{~}^{2}$-lactamase (NDM-1)-encoding gene in clinical Escherichia coli isolates recovered from companion animals in the United States. Antimicrob Agents Chemother 57: 2902-2903.

59. Stolle I, Prenger-Berninghoff E, Stamm I, Scheufen S, Hassdenteufel E, et al (2013) Emergence of OXA-48 carbapenemase-producing Escherichia coli and Klebsiella pneumoniae in dogs.J Antimicrob Chemother 68: 2802-2808.

60. Kempf M, Rolain JM, Diatta G, Azza S, Samb B, et al. (2012) Carbapenem resistance and Acinetobacter baumannii in Senegal: the paradigm of a common phenomenon in natural reservoirs.PLoS One 7: e39495.

61. Smet A, Boyen F, Pasmans F, Butaye P, Martens A, et al. (2012) OXA-23 producing Acinetobacter species from horses: a public health hazard. J Antimicrob Chemother 67: 3009-3010.

62. Kumsa B, Socolovschi C, Parola P, Rolain JM, Raoult D (2012) Molecular detection of Acinetobacter species in lice and keds of domestic animals in Oromia Regional State, Ethiopia.PLoS One 7: e52377.
63. Murugan MS (2015) Epidemiology of carbapenemase producing Escherichia coli isolated from calves. MVSc. Thesis, IVRI, Izatnagar, India (unpublished)

64. Elias LS, Konzen D, Krebs JM, Zavascki AP (2010) The impact of polymyxin $B$ dosage on in-hospital mortality of patients treated with this antibiotic. J Antimicrob Chemother 65: 2231-2237.

65. Bergen PJ, Landersdorfer CB, Zhang J, Zhao M, Lee HJ, et al. (2012) Pharmacokinetics and pharmacodynamics of 'old' polymyxins: what is new Diagn Microbiol Infect Dis 74: 213-223.

66. Sandri AM, Landersdorfer CB, Jacob J, et al. (2013) Population pharmacokinetics of intravenous polymyxin $b$ in critically ill patients: implications for selection of dosage regimens. Clinical Infectious Diseases 57: 524-531.

67. Castanheira M, Sader HS, Deshpande LM, Fritsche TR, Jones RN, (2008) Antimicrobial activities of tigecycline and other broad-spectrum antimicrobials tested against serine carbapenemase- and metallo-ß-lactamase-producing enterobacteriaceae: Report from the Sentry Antimicrobial Surveillance Program. Antimicrobial Agents and Chemotherapy 52: 570-573.

68. Hirsch EB, Tam VH (2010) Detection and treatment options for Klebsiella pneumoniae carbapenemases (KPCs): an emerging cause of multidrugresistant infection. Journal of Antimicrobial Chemotherapy 65: 1119-1125.

69. Samra Z, Ofira O, Lishtzinsky Y, Madar-Shapiro L , Bishara J (2007) Outbreak of carbapenem-resistant Klebsiella pneumoniae producing KPC-3 in a tertiary medical centre in Israel. International Journal of Antimicrobial Agents 30: 525529 .

70. Singh BR (2015) Development of strategies for management of infections with carbapenem resistant bacteria Myths and Facts.

71. Falagas ME, Kasiakou SK (2005) Colistin: the revival of polymyxins for the management of multidrug-resistant gram-negative bacterial infections. Clinical Infections and Diseases 40: 1333-1341.

72. Falagas ME, Kopterides $P$ (2007) Old antibiotics for infections in critically ill patients.Curr Opin Crit Care 13: 592-597.

73. Rose WE, Rybak MJ (2006) Tigecycline: first of a new class of antimicrobial agents.Pharmacotherapy 26: 1099-1110.

74. Endimiani A, Patel G, Hujer KM, Swaminathan M, Perez F, et al. (2010) In vitro activity of fosfomycin against blaKPC-containing Klebsiella pneumoniae isolates, including those nonsusceptible to tigecycline and/or colistin.Antimicrob Agents Chemother 54: 526-529.

75. Falagas ME, Giannopoulou KP, Kokolakis GN, Rafailidis PI (2008) Fosfomycin: use beyond urinary tract and gastrointestinal infections. Clin Infect Dis 46 1069-1077.

76. Michalopoulos AS, Livaditis IG, Gougoutas V (2011) The revival of fosfomycin Int J Infect Dis 15: e732-739.

77. Popovic M, Steinort D, Pillai S, Joukhadar C (2010) Fosfomycin: an old, new friend. Eur J Clin Microbiol Infect Dis 29: 127-142.

78. Raz R1 (2012) Fosfomycin: an old--new antibiotic.Clin Microbiol Infect 18: 4-7.

79. Roussos N, Karageorgopoulos DE, Samonis G, Falagas ME (2009) Clinical significance of the pharmacokinetic and pharmacodynamic characteristics of fosfomycin for the treatment of patients with systemic infections. International Journal of Antimicrobial Agents 34: 506-515.

80. Apisarnthanarak A, Mundy LM (2012) Carbapenem resistant Pseudomonas aeruginosa pneumonia with intermediate minimum inhibitory concentrations to doripenem: combination therapy with high dose, $4 \mathrm{~h}$ infusion of doripenem plus fosfomycin versus intravenous colistin plus fosfomycin. International Journal of Antimicrobial Agents 39: 271-272.

81. Dinh A, Salomon J, Bru JP, Bernard L (2012) Fosfomycin: efficacy against infections caused by multidrugresistant bacteria. Scandinavian Journal of Infectious Diseases 44: 182-189.

82. Souli M, Galani I, Boukovalas S et al. (2011) InVitro interactions of antimicrobial combinations with fosfomycin against KPC2 producing Klebsiella pneumoniae and protection of resistance development. Antimicrobial Agents and Chemotherapy 55: 2395- 2397.

83. Capone A, Giannella M, Fortini D, et al. (2013) High rate of colistin resistance among patients with carbapenem-resistant Klebsiella pneumoniae infection accounts for an excess of mortality. Clinical Microbiology and Infections 19 E23-E30. 
Citation: Bhardwaj M, Singh BR, Murugan MS, Prasannavadhana, Dubey S (2015)Emergence of Carbapenemase Producing Pathogens in Animals. Pharm Anal Acta 6: 379. doi:10.4172/21532435.1000379

84. Maltezou HC, Giakkoupi P, Maragos A, Bolikas M, Raftopoulos V, et al. (2009) Outbreak of infections due to KPC-2-producing Klebsiella pneumoniae in a hospital in Crete (Greece).J Infect 58: 213-219.

85. Mouloudi E, Protonotariou E, Zagorianou A et al. (2010) Bloodstream infections caused by metallo-beta-lactamase/Klebsiella pneumoniae carbapenemaseproducing K. pneumoniae among intensive care unit patients in Greece: risk factors for infection and impact of type of resistance on outcomes. Infection Control and Hospital Epidemiology 31: 1250-1256.

86. Tumbarello $M$, Viale $P$, Viscoli $C$ et al. (2012) Predictors of mortality in bloodstream infections caused by Klebsiella pneumoniae carbapenemaseproducing K. pneumoniae: importance of combination therapy. Clinical Infections and Diseases 55: 943-950.

87. Falagas ME, Karageorgopoulos DE, Nordmann P (2011) Therapeutic options for infections with Enterobacteriaceae producing carbapenem-hydrolyzing enzymes.Future Microbiol 6: 653-666.
88. Castanheira M, Sader HS, Jones RN (2010) Antimicrobial susceptibility patterns of KPC-producing or CTX-M-producing Enterobacteriaceae.Microb Drug Resist 16: 61-65.

89. Souli M, Galani I, Antoniadou A et al. (2010) An outbreak of infection due to betalactamase Klebsiella pneumoniae carbapenemase 2-producing K. pneumoniae in a Greek University Hospital: molecular characterization, epidemiology, and outcomes. Clinical Infections and Diseases 50: 364-373.

90. Jazani NH, Zartoshti M, Babazadeh H, Ali-daiee N, Zarrin S, et al. (2009) Antibacterial effects of Iranian fennel essential oil on isolates of Acinetobacter baumannii.Pak J Biol Sci 12: 738-741.

91. Fahey JW, Haristoy X, Dolan PM, et al. (2002) Sulforaphane inhibits extracellular, intracellular, and antibiotic-resistant strains of Helicobacte pylori and prevents benzo[a]pyrene-induced stomach tumors. Proceedings of National Academy of Science USA 99: 7610-7615

92. Khan R, Islam B, Akram M, Shakil S, Ahmad A, et al. (2009) Antimicrobial activity of five herbal extracts against multi drug resistant (MDR) strains of bacteria and fungus of clinical origin. Molecules 14: 586-597. 